\title{
Study on the Position and Reform Measures in Vocational School Chinese Teaching
}

\author{
Yanqin Yan ${ }^{1, a}$, Jianfeng $\mathrm{Wu}^{2, \mathrm{~b}}$ \\ ${ }^{12}$ Jiangxi College of Foreign Studies, Nanchang, Jiangxi, 330099 \\ ${ }^{\mathrm{a}}$ email, ${ }^{\mathrm{b}}$ email
}

Keywords: Vocational School Chinese Teaching, Position, Reform Measures

\begin{abstract}
In recent years, our vocational and technical education institutions have set off a wave of reform programs. University Chinese language teachers have disadvantaged and do not want this wave totally ineffective. Although scholars generally recognized the importance for the Humanistic Education Personnel Training in vocational college, language education in vocational education has not significantly changed. This paper believes that China vocational college language courses should respect teachers' research, consultation and professional culture, and teacher development programs must fully understand the capabilities and capacity for innovation, promote their professional development through the process of designing the course.
\end{abstract}

\section{Introduction}

Present of Higher Vocational Education in schools are: short-term vocational universities, vocational and technical colleges, general College, an independent set of adult institutions, vocational education in the colleges established only child structure (Secondary College), with higher academic qualifications of private colleges and universities. Vocational College principal training required for the economic development of application-oriented, technology-based advanced technology and management personnel. It then Masters (Professional Master's degree or an advanced professional certificate) from college (diploma or certificate post three books) to occupational undergraduate (bachelor's degree or post certificate). According to local needs, the industry's economic and social development, in accordance with the actual needs of the technical field and professional positions (group) to set and adjust a professional, self-determined by the contractor school, the provincial education administrative departments for approval. The Ministry of Education developed a "special vocational education sub Setup Guide" to guide the higher vocational school professional setup.

\section{Orientation of College Chinese Course in Higher Vocational School}

Higher Vocational education is employment-oriented education and training is the application of high-quality talents, and its proposed curriculum and general education significantly different requirements. Therefore, all higher vocational school are actively working to inherit from colleges and universities from the curriculum system reform. Vocational Training courses must focus on professional competence, curriculum development and design work based on the pursuit of Teaching Jun, occupational status of work items isomorphism, fully embodies the occupation, practicality and openness requirements. As Chinese university vocational education curriculum reform is also faced with this requirement. College Chinese in order to occupy a place in the vocational education curriculum system must meet the requirements of vocational education programs and services in vocational education and training talented professional and technical field related professional positions Qualifications.

Vocational education is employment-oriented education, highlighting the culture of professional competence. In educational practice, there is a deviation on the ability to know some vocational school, the vocational ability merely as vocational skills, ignoring the human factors contained therein. Reflected in the Curriculum System, it is to increase the proportion of vocational skills courses, neglect or even no humanities courses. Educational concepts such quick success to ignore 
students' body characteristics, the students have no feelings and values as a mechanical existence. The arrival of the industrial age really needs to cultivate the skills to operate a highly efficient application of talent, but it is another tool of the people, the risk of alienation. Science and technology are to produce a single practical education and a growing negative impact on the training of personnel. Moreover, in the practice of vocational education personnel training, we see that blindly strengthening skill training, ignoring students' emotion, culture and values of the perfect personality, it backfired. Some Vocational College Students' Tiredness can not say that there is no incentive in this regard. Therefore, higher vocational school university language courses as a humanities course, should play an important role in vocational education curriculum system in. Language Teaching hand to guide the students to experience the authors noble morality and profound thought, contributing to develop its sound personality and quality formation; the other but rather to focus on students' overall unsustainable development, students of professionalism , so that the language knowledge learned to help their career development.

Through classroom teaching and other forms of human conscious students to carry out the traditional culture and education, to enable students to understand the Chinese people's moral (Lu), and comprehensively improve the quality of cultural and moral education of college students is an important task to be undertaken by the one. Mother tongue is the foundation of national culture and ties, it is a spiritual home nation, university language as their mother tongue course, has the responsibility and the ability to bear the historical responsibility. Higher education stage and only university language courses are able to assume this responsibility. Professor Zhong Qiquan wrote: We want to say to transcend language tools Language and Culture said. Heidegger said: Language is there home. That is in itself a cultural heritage activities mother tongue education, culture its people's national sentiment, and enhance national cohesion are of great significance. Ancient Western Arts free seven first three: grammar, rhetoric, logic is the language content: in ancient Chinese language education and language learning is a lifelong career learners.

\section{Question in Current Chinese Curriculum Reform in Higher Vocational School}

Development of Vocational Education Curriculum copy was once common phenomenon of undergraduate education, the problem has not been completely resolved. With the rapid development of science and technology, new emerging profession, occupation disappearing old connotation of professional positions are constantly changing, higher vocational education has emerged professional continue to expand the width of the trend. Be proficient in a narrow vocational training in the field of vocational education and blindly follow a pattern education undergraduate education models have been unable to meet the need vocational development. Higher Colleges language university courses in this educational transformation should also be responsive to the needs of the reform of vocational and technical education, to cross curriculum research.

Imperative language curriculum reform in vocational school is to reshape the discipline targeting university language by developing new interdisciplinary research field, giving it depth and proper discipline dignity. And this party, medical humanities general education courses Chinese Taipei Medical College) Medicine and Higher Colleges of art to our cross-language courses bring a lot of inspiration. This course covers the concept of beauty logical concept in Western thought history of aesthetics, the relationship between the relationship between aesthetic categories system of beauty and ugliness sublime tragedy and comedy, art and medicine, music and medicine, literature and medicine, genius tragedies, Shakespeare in the medical, Dream of Red Mansions disease and influence, lotus feet) eternal pain from women of foot pain to the hearts of Chinese people, who stone originality as a source of) depression, Cao Cao's headache with his character, li Bai the death of Du Fu creative Psychology, Beethoven's deafness, asthma and Yan Fu returning to the retro, ARTEL spiritual world, a total of 16 speak. This course examines the relationship between the cross-cutting nature of Medicine and Science, between art, the medicine is reduced to the study of human science, seek medical in the art as also to explore the art of infiltration in the medical field. In addition to two cross medicine and arts disciplines, but also related to aesthetics, literature, psychology, sociology and other disciplines, it is to help students expand their horizons from the 
perspective of cross found the profession and the wider use powerful force development students look professional unique vision, comprehensive humanities students solid training and life-saving medical care road. Sometimes content is organized by topic course, the same core emphasize different perspective of knowledge complement each other, mutual integration, complement each other, creating a collusion between the knowledge network, and ultimately to help students correctly understand themselves, find others, understanding society, completed the human education goal of complete development.

University language teachers curriculum consciousness awakening, language courses and professional skills courses cross development, we need to avoid biased selection of some of the teachings, such as some language teachers have only educational activities based on the nature of the language common theme or topic, and the lack of the overall structure and associated infrastructure, learning to become some do not review or verify the quality of the tool. Without learning and exchange concepts, students' understanding solid enough and rich. Some teachers put this learning to become project-based learning, I thought, this is misinterpreted project-based learning concept. The main problem with this item suspected day of learning: First, put together a patchwork language lessons and courses became a term of skills courses. Teachers curriculum understanding of the concept is not clear, the curriculum does not reflect the true meaning of knitting courses converged, let students choose the content. Learning Resources select the stream to a patchwork of texts even polymerization terminology. Second, disintegration) course become chowder language lessons and other courses, which shows the contents of the debris and the dispersion of a plurality of subjects, there is no knowledge of the structure of the different disciplines, skills, attitudes do meaningful integration, students can not only experience linked meaningful learning experiences rather fragmented, partial and lengthy study, students key concepts can not fully grasp. Third, the language courses to other disciplines tilt in the design process, weakening the nature of general education and mother tongue education itself has become a subsidiary of courses of professional skills courses, or to become an education campaign programs. The emergence of these problems teachings, language teachers must draw the attention of higher vocational school. Learning project itself is not necessarily suitable for teaching, simply use the project concept, but a fashionable practice, is not conducive to the development of students into the language curriculum even further jeopardy.

To change the teacher's role. Most conventional courses in operation, is positioned on the role of teachers in curriculum implementers, only the implementation of the rights established curriculum, without right to participate in decision-making courses. Chinese college reform in higher vocational school must change the dominant school of power relations, the promotion of pluralistic expression of sound, creating a shared responsibility of curriculum research atmosphere. Language courses for teachers involved in university decision-making, correct, proper and in good faith to express their views and opinions of others appropriately questioned.

\section{Conclusion}

Curriculum Localization of Polytechnic University has been plagued by a line of teachers and curriculum researchers. This positioning dilemma is a microcosm of the 21st century School education curriculum profound changes. Spiritual heritage of Chinese traditional culture has faced a painful process of cultural conflict and cultural choice. Orientation of Vocational school language course is the education of both change and will inevitably lead to the selection. Over the years the university curriculum practice language mixed, which produce a lot of problems. The key question is vague awareness programs, courses and cultural conservative curriculum objectives. Blindly follow the trend or, stand still worth mentioning, language courses has embarked on the road of transformation. I believe that attitude is an open course Chinese college reform in higher vocational school should look. This openness, communication and performance courses in professional learning, open and inclusive dialogue classroom curriculum and researchers work together to jointly build a knowledge platform. 


\section{Acknowledgements}

Project Fund: 2013 College Humanity subject item of Jiangxi Province (JY1347).

\section{References}

[1] Department of Theoretical and Experimental Education University of Liège Equity in European educational systems: A set of indicators (February 2005 - 2nd Edition) [J]. A project supported by the European Commission Directorate General of Education and Culture Project Socrates SO2 -61OBGE, 2005.

[2] Fernando Reimers. Unequal Schools, Unequal Chances: The Challenges to Equal Opportunity in the Americas Cambridge: Harvard University Press, 2000.

[3] Fine L R, Hsu T P, King K G, Janow J D, Weil G, Llp Education. Federal Rights and Racial Equity, Adequacy, and Standards in K-12 Education [J]. New York: Lawyers' Committee for Civil Rights under Law, June 2003.10.

[4] Gewirtz, S., Ball, S.J, \& Bowe, R.markets. choice and equity in education Buckingham, UK. Open University Press.1995.

[5] Jane Bates, sue Lewis and Andy Pickard. Education Policy, Practice and the Professional continnum [M].intern ational publishing group, 2010.4.127. 